\title{
Combined effect of environmental factors on distribution of Geometridae (Lepidoptera) in South Korea
}

\author{
SeI-Woong CHOI ${ }^{1}$ and Jung-Hwa CHUN ${ }^{2}$ \\ ${ }^{1}$ Department of Environmental Education, Mokpo National University, 61 Dorim-ri, Chungkye, Muan, Jeonnam 534-729, \\ South Korea; e-mail: choisw@mokpo.ac.kr \\ ${ }^{2}$ Division of Forest Ecology, Korea Research Institute, 207 Cheongyangni 2-dong, Dongdaemun-gu, Seoul 130-712, South Korea
}

Key words. Geometridae, habitat diversity, geography, climate, peninsular effect, South Korea

\begin{abstract}
We analyzed patterns of geometrid species richness in South Korea to assess the observed and estimated species richness gradient, to determine predictors for the distribution of moths and to investigate the effect of latitude on the species richness of moths in the Korean peninsula. The species richness was analyzed for 541 geometrid moths across 17 quadrates, with each quadrate defined by one degree of latitude and longitude. Two subgroups of geometrid moths were adopted according to their distributional ranges: Palearctic (435 species, 80.4\%) and Oriental (106 species, 19.6\%). To investigate the relationship between the distribution of geometrid moths and environment, eight variables were used. The estimated species richness of geometrids was calculated using the Chao 2 estimator because there was uneven sampling effort across the quadrates. Due to multicollinearity we used covariance values produced by principal component analysis and the first four axes adopted have eigenvalues $\geq 1.0$. Two models of regression analyses were applied based on multiple linear regression using eight variables (model I) and principal components axes (model II). Of the two subgroups of geometrid moths the Palearctic species richness increased with latitude, but not that of Oriental species richness. A combined effect of abiotic (maximum altitude, temperature, rainfall, and latitude) and biotic (plant species richness and vegetation) variables was indicated by both models of regression analyses. The different effect of each spatial and environmental predictor on the distribution of geometrid moths on the Korean peninsula is discussed. The significant relationship between estimated species richness and latitude indicate a peninsular effect on geometrid moths in South Korea.
\end{abstract}

\section{INTRODUCTION}

The Korean peninsula is elongated, surrounded by ocean to the west, south and east, and connected to the Asian continent in the north. Biogeographically it is classified as in the Palearctic region, and its biotic component is largely of Palearctic or Oriental origin. The north-tosouth orientation of the peninsula, along with several mountain chains, has created a diversity of conditions, resulting in a relatively high diversity of species (Shin, 2002). The current political situation divides the Korean peninsula. South Korea, the southern part of the peninsula, bordered by North Korea, is located at ca. $34^{\circ}$ to $381 / 2^{\circ} \mathrm{N}$ and $126^{\circ}$ to $129^{\circ} \mathrm{E}$, and has an area of 100,032 $\mathrm{km}^{2}$.

Geometrid moths are one of the largest species groups of Lepidoptera, with about 21,700 species globally (Scoble, 1999). Being primary consumers and having high habitat fidelity, geometrid moths represent a suitable taxon for ecological and biogeographical studies (Intachat et al., 2001; Beck et al., 2002; Brehm \& Fiedler, 2003; Axmacher et al., 2004). On the Korean peninsula, the total moth species richness is estimated to be about 3,000 species, and geometrid moths, with about 650 species, one of the dominant moth groups, along with Noctuidae and Pyralidae (Choi, 2006).

Large scale bioinventory projects are usually confronted with problems of data quality (Dennis et al., 1999; Rahbek \& Graves, 2001). For example, studies of but- terfly distribution in England (Dennis et al., 1999) and Finland (Luoto et al., 2006) show that sites with high species richness generally have more species records. This is due to recorders' preference for visiting sites that are known to have high species richness or are known to harbour populations of rare species. This observation is also pertinent to the study of moths. Although moths are easily collected using light traps, they have not been systematically sampled in most country for inventorying purposes. Most surveys of geometrid moths on the Korean peninsula were for certain areas such as high mountains with easy access, national parks, or places near research institutes or universities, which produces strongly biased and unevenly distributed records. Nevertheless, Hortal et al. (2004) suggest information from even incomplete and sparse sampling has provided useful data for assessing or predicting biodiversity.

The objectives of the present study were (1) to assess the observed and estimated species richness gradient of geometrid moths across quadrates of South Korea, (2) to determine environmental predictors for the distribution of geometrid moths in South Korea, and (3) to investigate the effect of latitude on the species richness of geometrid moths in South Korea. These questions were addressed by compiling a database on the distribution of Geometridae, climate and geographic features of South Korea. 


\section{MATERIAL AND METHODS}

\section{Moth data}

Currently, the Korean Geometridae includes about 650 species (Choi, 2006), and in this study we analyzed 541 species from six subfamilies, which is $83 \%$ of total geometrid moth fauna. The excluded species occur exclusively in either the northern part of the Korean peninsula (i.e., North Korea) or on the southern islands (e.g. Jeju Island). Data used to establish species richness comprised 3,864 records, mostly $(3,371$ records, 87\%) obtained from Shin (1996), who compiled taxonomic and distributional information on geometrid moth species from 1883 to 1996 . Since 1996 we have collected additional distributional data on the geometrid moths of South Korea and added them to the database. Because the raw data from Shin (1996) were based on locality names without geographic information (e.g. latitude, longitude), we transformed the localities into geographic points using summits for mountains or centers for towns and villages.

To assess the patterns of geometrid species richness, we divided South Korea into 17 quadrates bounded by meridians of latitude and parallels of longitude at one-degree intervals (Fig. 1). Because the distributional data for geometrid moths was not comprehensive, it was not enough to generate a fine-scale map. The geometrid moths used in the present study were divided into two groups based on their distributional ranges, since Palearctic and Oriental elements make up the biota of the Korean peninsula. The Palearctic moths, which are distributed widely from Europe to the Russian Far East, China and Japan, comprise 435 species $(80.4 \%)$. The Oriental species, which occur in northern India, southwestern China, Taiwan and southern Japan, comprise 106 species (19.6\%), respectively. These percentages of Palearctic and Oriental are similar to that reported for butterflies (Choi, 2004).

Our moth data was obtained using uneven sampling efforts. We calculated the estimated number of geometrid species using the Chao 2 estimator and software EstimateS (ver. 8.0; Colwell, 2006). The Chao 2 estimator is the sum of the observed number of species and the quotient $\mathrm{a}^{2} / 2 \mathrm{~b}$ ( $a$, the number of unique and $b$, the number of duplicate records), and was used here because it is suitable for different kinds of data (Colwell \& Coddington, 1994). In the present analysis, unique and duplicate species indicate one and two site(s) for the species in a quadrate, respectively. The observed and estimated numbers of species were log-transformed to normalize the distributions before analysis.

\section{Predictor variables}

Variability in species richness is affected by a combination of abiotic and biotic factors across spatial scales from local to regional levels (Rahbek \& Graves, 2001; Hawkins et al., 2003). A total of eight variables were documented for each quadrate. The variables were latitude $\left(34^{\circ} \mathrm{N}-38^{\circ} \mathrm{N}\right)$, longitude $\left(126^{\circ} \mathrm{E}-129^{\circ} \mathrm{E}\right)$, area $\left(\mathrm{km}^{2}\right)$, maximum altitude $(\mathrm{m})$, rainfall $(\mathrm{mm})$, number of plant species, vegetation index and mean of monthly average temperatures.

The geometric predictors, latitude, longitude and area, were included since the north-to-south orientation of the peninsula and east-to-west topographic change might affect the spatial pattern of species richness. Latitude and longitude were coded by the left side and base of the quadrate, respectively. Area, one of the most powerful predictors of species richness, was included because it varied among quadrates, being much smaller in marginal ones. Maximum altitude was included for an indirect measure of habitat diversity (Rosenzweig, 1995). Area and maximum altitude were obtained using the Digital Elevation Model with a 3 arc-second $(90 \mathrm{~m})$ resolution.

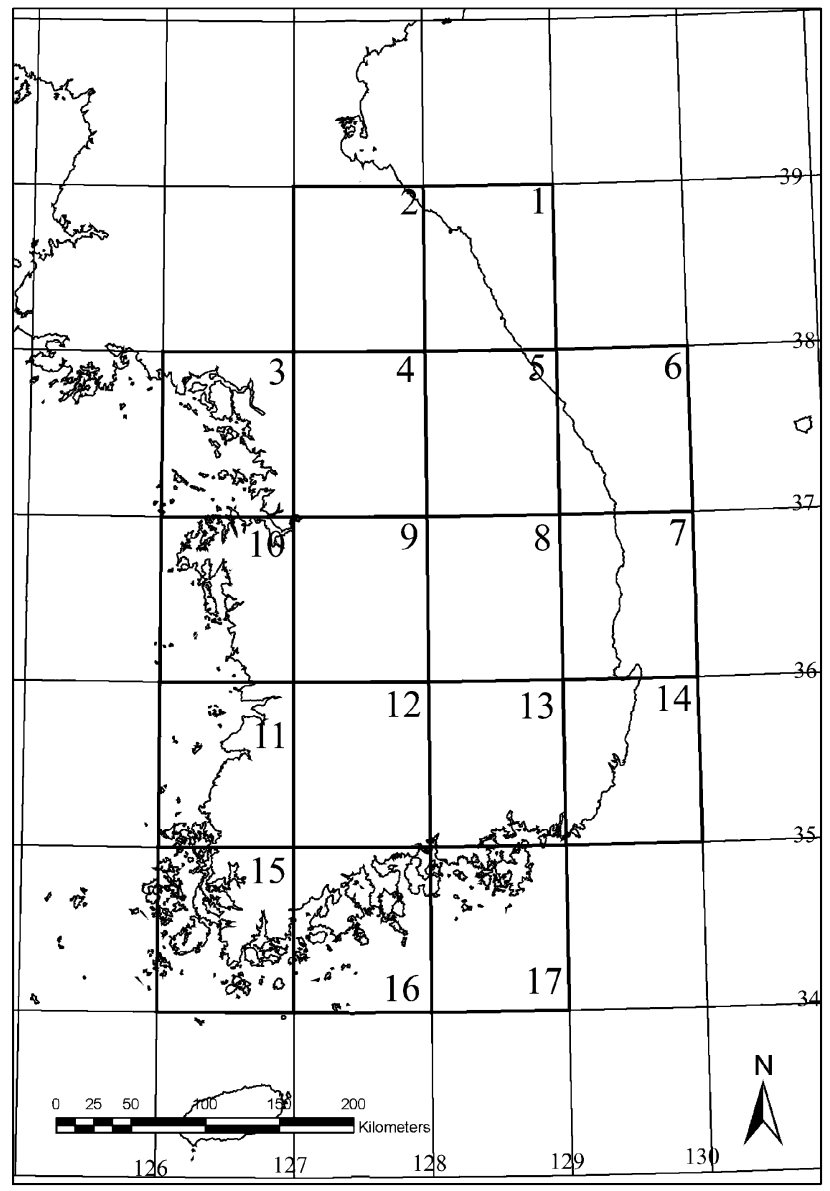

Fig. 1. Seventeen quadrates in South Korea. Number in upper right corner of each quadrate indicates quadrate number.

The vegetation index was the product of MOD13 derived from MODIS satellite images and ranged between -0.2 and 1.0, which the higher the value the denser the vegetation. The values for vegetation used in the present analyses were averages of 16 days from Julian days $210-225$ of 2004 . Temperatures $\left({ }^{\circ} \mathrm{C}\right)$ were the yearly mean of the monthly average temperatures from 1970 to 2000 . Annual rainfall (mm) was the mean of yearly rainfall from 1970 to 2000 . Lobo et al. (2001) show that the pattern of plant species richness is strongly correlated with maximum altitude on the Iberian Peninsula and Balearic islands. For this study it was not possible to obtain the total number of plant species in each quadrate. Thus we used a surrogate, derived from number of plant species on the tallest mountain in each quadrate.

\section{Analysis}

The relationship between spatial and environmental predictors and the richness of geometrid moths in South Korea was assessed based on two independent models. Stepwise multiple regression model (Model I) was used to determine the environmental factors that affect the richness of geometrid moths. The SPSS/PC+ program packages were used for statistical analysis (SPSS Inc., 2005).

Graham (2003) noted the problem of multicollinearity in analyzing ecological data, which causes inaccurate model parameterization, decreases statistical power and excludes significant predictor variables during model creation. He reviewed three alternative approaches, residual and sequential regression, principal components analysis (PCA) regression, and structural 
TABLE 1. Observed and estimated (Chao 2) species richness and number of sampling sites in each quadrate. See Fig. 1 for the quadrate number. Numbers in parenthesis followed by observed species richness indicate number of Palearctic and Oriental elements, respectively.

\begin{tabular}{cccc}
\hline Quadrate & No. sampling sites & Observed species richness & Estimated species richness \\
\hline 1 & 10 & $211(165,46)$ & 477 \\
2 & 6 & $170(137,33)$ & 2979 \\
3 & 8 & $68(49,19)$ & 402 \\
4 & 20 & $286(231,55)$ & 364 \\
5 & 13 & $251(205,46)$ & 446 \\
6 & 2 & $80(62,18)$ & 167 \\
7 & 5 & $35(25,10)$ & 492 \\
8 & 11 & $118(88,30)$ & 197 \\
9 & 10 & $115(79,36)$ & 180 \\
10 & 11 & $84(64,20)$ & 309 \\
11 & 11 & $155(110,45)$ & 405 \\
12 & 9 & $255(195,60)$ & 128 \\
13 & 17 & $81(51,30)$ & 77 \\
14 & 7 & $40(25,15)$ & 294 \\
15 & 7 & $224(162,62)$ & 161 \\
16 & 4 & $78(51,27)$ & 263 \\
\hline
\end{tabular}

equation modelling, and commented on the strong and weak points of each approach.

We performed PCA with a total of eight variables using PC-ORD (ver 5.12; McCune \& Mefford, 2006). To generate PCA scores we first modified the independent variables by the general relativization method (McCune \& Mefford, 2006). The correlation matrix was used for the cross-product matrix because it takes the standardized form of the matrix and, therefore, if variables have been measured using different scales this will not affect the analysis (Field, 2000). The minimum loading coefficient was 0.50 for including an independent variable in the interpretation of a given principal component. Backward stepwise regression model (Model II) was produced using the scores of the principal components as predictor variables, and PCA axes with an eigenvalue $\leq 1.0$ were excluded (Graham, 2003). The SPSS/PC+ program packages were used for statistical analysis (SPSS Inc., 2005). The Mantel test was applied to investigate the pattern of the correlation between the dissimilarity of geometrid species and quadrate distance. Quadrate distance was generated from the standardized ratio between quadrate mid-points. The Mantel test was run 999 times with randomized data in a Monte Carlo test of significance using PC-ORD (ver. 5.12; McCune \& Mefford, 2006).

\section{RESULTS}

The diversity of geometrid moths in each quadrate varied from a minimum of 35 species (quadrate 7) to a maximum of 286 species (quadrate 4) (Table 1). Although sampling effort did not significantly affect species richness (Pearson's $r=0.48, P=0.057$ ), it was suspected that the quadrates with exceptionally high or low species richness were due differences in sampling effort. On the other hand, the estimated species richness using Chao 2 identified a different maximum (quadrate 8 with 492 species) and minimum (quadrate 14 with 77 species) (Table 1). The Sørensen dissimilarity of species and the Euclidian distance between quadrates were correlated (Mantel test $r=0.196, P<0.05$ ), suggesting that the spe- cies richness of geometrid moths may show a pattern of decreasing richness with distance similar to that in other groups.

Species richness of the moths belonging to the two biogeographic elements, Palearctic and Oriental, differed in their responses to latitude and longitude (Figs 2, 3). The species richness of the Palearctic element increased as latitude increased, while that of the Oriental element did not increase as latitude increased. The species richness of the Palearctic element was highest in the middle longitudes, while that of the Oriental element was higher in the middle and the northeast.

Stepwise regression analyses of eight variables (Model I) showed that plant species richness was the main predictor for observed $\left(\mathrm{R}^{2}=0.19, F_{1,15}=4.83, P<0.05\right)$ and estimated $\left(\mathrm{R}^{2}=0.21, F_{1,15}=5.25, P<0.05\right)$ species rich-

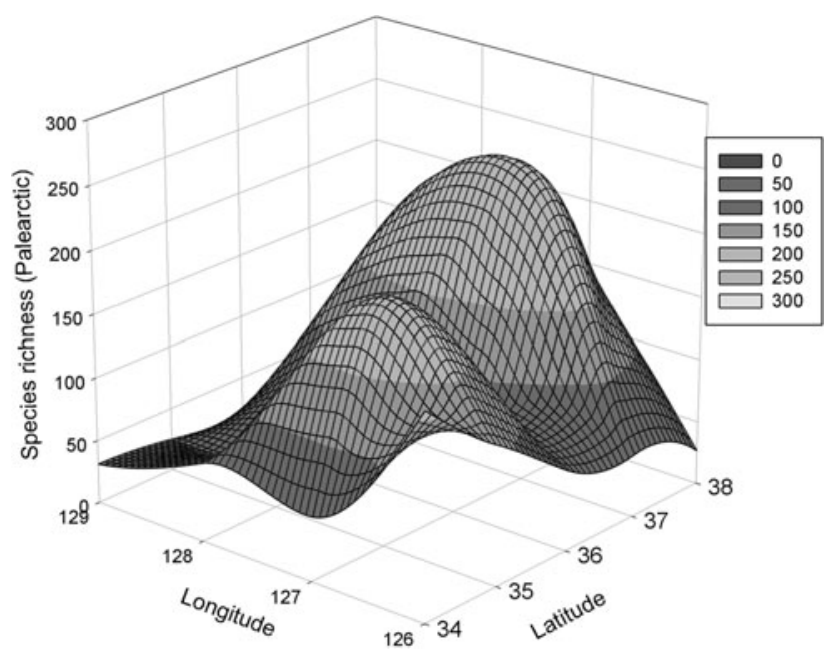

Fig. 2. Pattern of richness of Palearctic species along latitude and longitude. 


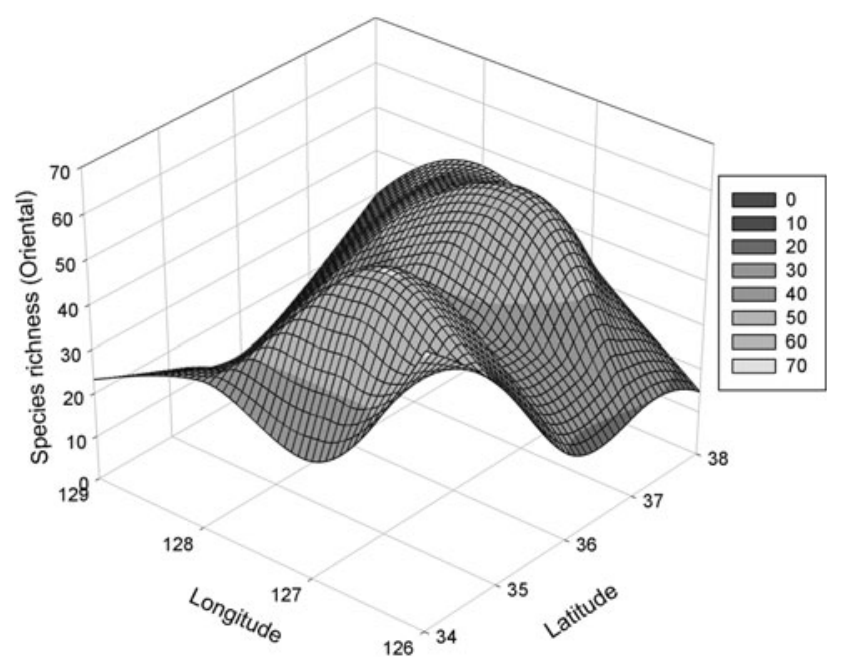

Fig. 3. Pattern of richness of Oriental species along latitude and longitude.

ness, and plant species richness, longitude, rainfall and vegetation index for the species of the Oriental element $\left(\mathrm{R}^{2}=0.72, F_{4,12}=11.12, P<0.005\right)$ (Table 2$)$.

The PCA partitioned the eight spatial and environmental variables into four axes with eigenvalues $\geq 1.0$ (Table 3, Fig. 4). The first four principal components explained $89.7 \%$ of the variance in independent variables among the 17 quadrates. The first axis accounted for $43.3 \%(\lambda=3.47)$ of the variability and loaded five variables: maximum altitude, average temperature, vegetation, latitude and area. Except for temperature (loading $=-0.83$ ), all variables were loaded positively (loading $\geq 0.58)$. The second axis explained $18.6 \%(\lambda=$ 1.49) of the variability and identified three predictors, longitude (loading $=-0.81$ ), area (loading $=0.58$ ) and plant species richness (loading $=0.53$ ). The third axis explained $16.2 \%(\lambda=1.22)$ of the variability and identified two predictors, latitude (loading $=-0.68$ ) and temperature (loading $=0.54$ ). The fourth axis explained $12.6 \%(\lambda=1.01)$ of the variability and identified one strong negative predictor, rainfall (loading $=-0.93$; all others $\leq 0.24$ ).

A backward stepwise regression model using the four principal component axes (Model II) revealed that the observed species richness was significantly affected by variation in the first, second and fourth axes $\left(\mathrm{R}^{2}=0.54\right.$, $\left.F_{3,13}=7.27, P<0.005\right)$. The Palearctic element was significantly affected by variation in the first, second and

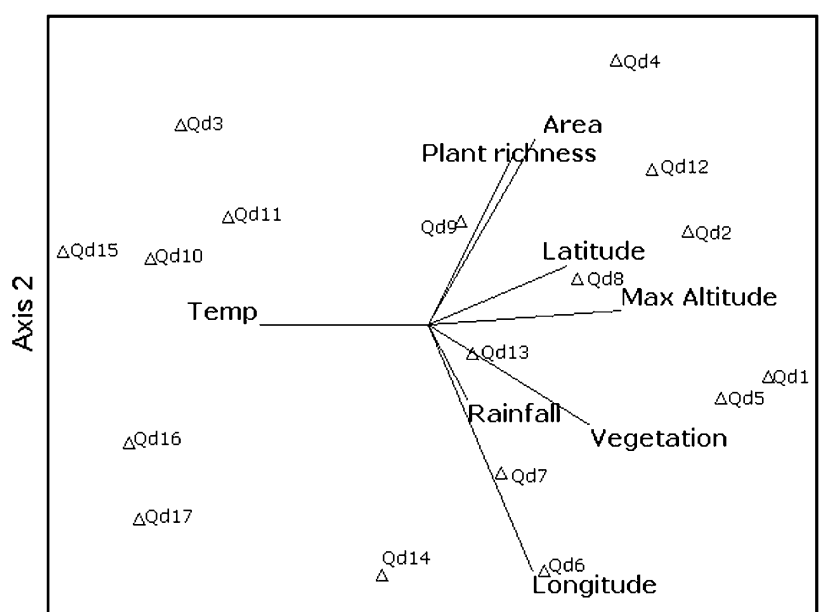

Axis 1

Fig. 4. PCA Ordination graph of eight variables (lines with bold letters) and 17 quadrates (triangles with quadrate number) on two principal axes. The graph shown here was rotated $-3^{\circ}$. Lines in the same direction indicate positively correlated variables and those in the opposite direction negatively correlated variables. Eigenvalues of PCA axis $1=3.47$ and PCA axis $2=$ 1.49. Abbreviations. Temp - average temperature and Max Altitude - maximum altitude.

fourth axes $\left(\mathrm{R}^{2}=0.56, F_{3,13}=7.68, P<0.005\right)$, but the Oriental element was significantly affected by variation in the second, third and fourth axes $\left(\mathrm{R}^{2}=0.55, F_{3,13}=7.41\right.$, $P<0.05$ ), respectively (Table 4 ). The estimated total species richness was affected by variation in the first axis $\left(\mathrm{R}^{2}\right.$ $=0.22, F_{2,14}=3.24, P=0.070$ ).

The correlation between the log-transformed observed and estimated species richness and the first axis showed an obvious quadratic increasing tendency (observed species richness $\mathrm{R}^{2}=0.53, F_{2,14}=7.94, P<0.01$; estimated species richness $\mathrm{R}^{2}=0.41, F_{2,14}=4.74, P<0.05$, respectively) (Figs 5, 6). The relationship between observed and estimated species richness and axis 1 showed that the quadrates in the upper right corner of the graph (e.g., 1, 2, $4,5)$ are located in northeastern South Korea, and those in the middle left corner of the graph (e.g. 3, 10, 11, 16, 17) in western and southern coastal areas of South Korea.

The relationship between observed and estimated species richness and latitude was examined to determine whether there is a peninsular effect on geometrid moths in South Korea (Fig. 7). The estimated species richness significantly increased with latitude (Pearson's $r=0.52, \mathrm{P}<$ $0.05)$, but the observed species richness did not (Pear-

TABLE 2. Model I summary of regression analysis for geometrid moths in 17 quadrates in South Korea against 8 spatial and environmental variables. Independent variables, plant species richness, rainfall and vegetation index, were log-transformed. Palearctic element was not shown since it did not have statistically significant predictor.

\begin{tabular}{|c|c|c|c|c|c|c|}
\hline \multirow{2}{*}{ Dependent } & \multirow{2}{*}{$R_{\mathrm{adj}}^{2}$} & \multirow{2}{*}{$\begin{array}{c}\text { ANOVA } \\
F \text {-ratio }\end{array}$} & \multicolumn{4}{|c|}{ Independent variables $(b)$} \\
\hline & & & Plant species richness & Longitude & Rainfall & Vegetation \\
\hline Observed species richness & 0.193 & $4.826^{*}$ & $0.493^{*}$ & & & \\
\hline Oriental element & 0.717 & $11.118^{* *}$ & $0.337 *$ & $-0.828 * *$ & $0.449^{*}$ & $0.509^{*}$ \\
\hline Estimated species richness & 0.210 & $5.254^{*}$ & $0.509^{*}$ & & & \\
\hline
\end{tabular}

$* P<0.05,{ }^{* *} P<0.005$ 


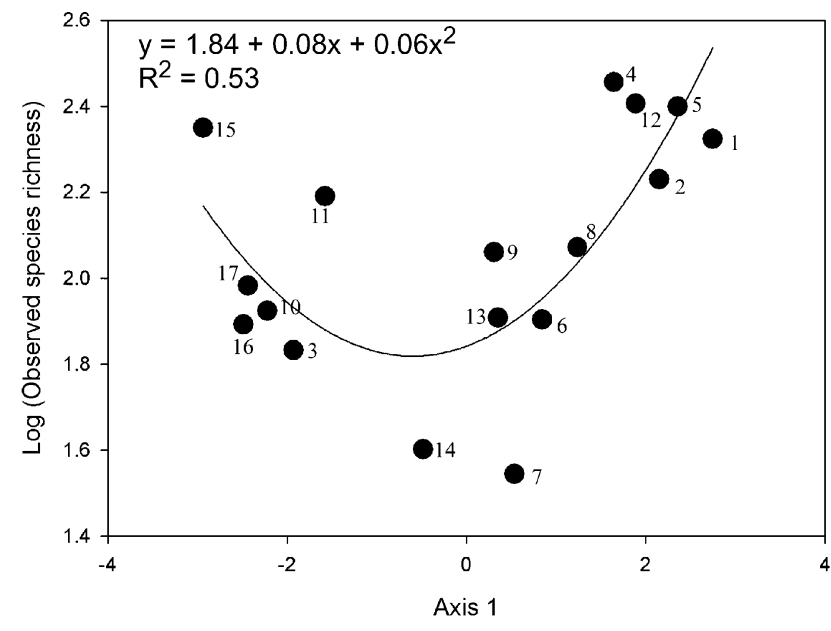

Fig. 5. Log-transformed observed species richness along the first PCA eigenvector and estimated regression curve $(P=$ $0.005)$. Dot with a number indicates the quadrate number.

son's $r=0.24, \mathrm{P}=0.36$ ). This indicates there is a peninsular effect on the distribution of geometrid moths in South Korea.

\section{DISCUSSION}

It is now widely accepted that the pattern of diversity on peninsulas may be a result of several factors, such as geographic orientation, ecological constraints, historical events and habitat diversity (Wiggins, 1999; Rahbek \& Graves, 2001; Tubelis et al., 2007). On the Korean peninsula the combined effect of latitude and habitat diversity is recorded for butterfly species (Choi, 2004). The species richness of geometrid moths in South Korea was largely influenced by a combination of abiotic (maximum altitude, temperature, area and latitude) and biotic (vegetation and plant species richness) variables (Tables 3, 4).

To reveal the predictors of geometrid distribution in South Korea, two regression analyses were applied. Model I with eight variables identified one predictor, plant species richness (Table 2), while model II with four principal components axes identified a combined effect of

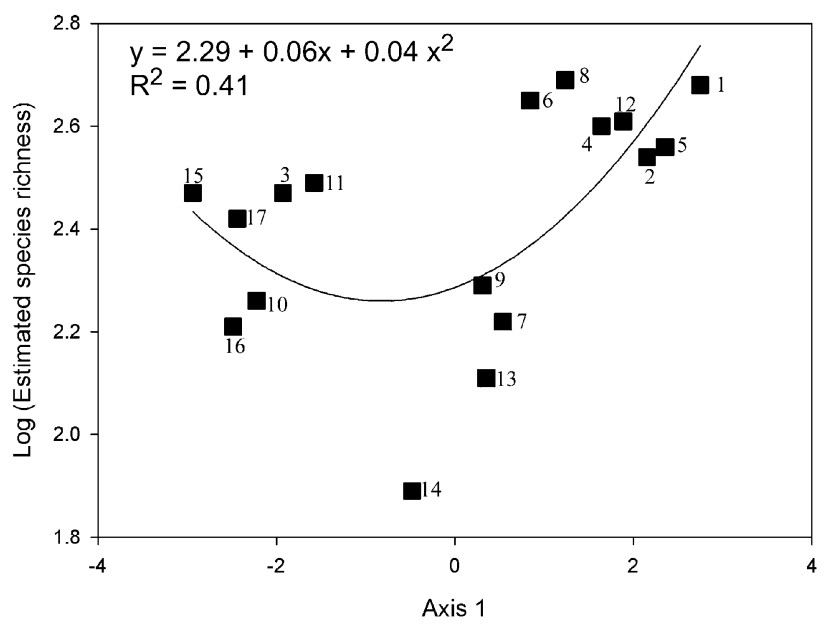

Fig. 6. Log-transformed Chao 2 estimated species richness along the first PCA eigenvector (squares) and estimated regression curve $(P=0.02)$. Square with a number indicates the quadrate number.

predictors (Table 4). The multiple linear regression analysis indicated a model with the lowest number of variables explaining the greatest variability in the response and accurately parameterized the regression coefficients for those variables. However, this approach has a major drawback in calculation of partial regression coefficients when the predictors are not independent due to multicollinearity (Mac Nally, 2000; Graham, 2003). This problem can be overcome by using the principal components axes in the regression analysis (Legendre \& Legendre, 1998; Graham, 2003). Since principal components are orthogonal, the regressions of principal components produces more stable results than partial regressions, and the rank of marginal statistics do not fluctuate with the adding or removing of variables (Graham, 2003). In the present study, the model II with PCA axes was favoured, based on data independence and explanatory power. A multicollinearity was observed in the geometrid data set $(25 \%$ of pairs of Pearson's $r$-value were significantly correlated at $P<0.05)$; and the mul-

TABLE 3. Results of PCA analysis for eight spatial and environmental variables measured in 17 quadrates of South Korea. Each variable was transformed by general relativization before analysis. Minimum loading coefficient was 0.50 for including an independent variable in the interpretation of a given principal component (bold numbers). PCA axes with an eigenvalue $\leq 1.0$ were excluded.

\begin{tabular}{lcccc}
\hline & \multicolumn{4}{c}{ Principle component axis } \\
\cline { 2 - 5 } & 1 & 2 & 3 & 4 \\
\hline Latitude & $\mathbf{0 . 7 0}$ & 0.17 & $\mathbf{- 0 . 6 8}$ & -0.01 \\
Longitude & 0.45 & $-\mathbf{0 . 8 1}$ & 0.11 & 0.18 \\
Area $\left(\mathrm{km}^{2}\right)$ & $\mathbf{0 . 5 8}$ & $\mathbf{0 . 5 8}$ & 0.25 & 0.15 \\
Average temp. $\left({ }^{\circ} \mathrm{C}\right)$ & $\mathbf{- 0 . 8 3}$ & 0.03 & $\mathbf{0 . 5 4}$ & 0.07 \\
Maximum altitude $(\mathrm{m})$ & $\mathbf{0 . 9 5}$ & 0.01 & 0.22 & -0.04 \\
Rainfall $(\mathrm{mm})$ & 0.18 & -0.25 & 0.12 & $-\mathbf{0 . 9 3}$ \\
Vegetation index & $\mathbf{0 . 7 7}$ & -0.35 & 0.40 & 0.24 \\
Plant species richness & 0.46 & $\mathbf{0 . 5 3}$ & 0.40 & -0.18 \\
Eigenvalue & 3.47 & 1.49 & 1.22 & 1.01 \\
Cumulative variance explained by axis $(\%)$ & 43.31 & 61.92 & 77.11 & 89.70 \\
\hline
\end{tabular}




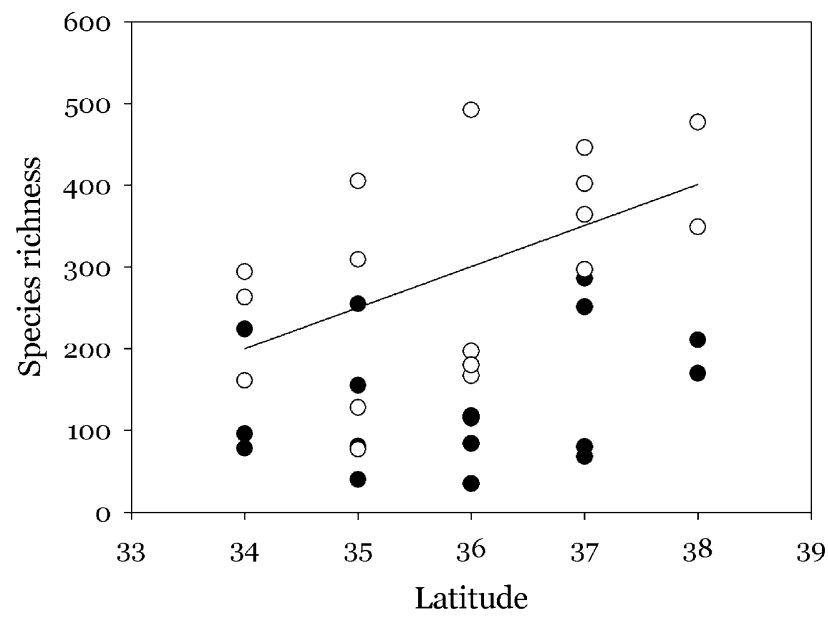

Fig. 7. Relationship between the observed (dark circle) and estimated (open circle) species richness and latitude. The regression line between the estimated species richness and latitude was significant (Pearson's $r=0.520, P<0.05$ ), while the regression line between observed species richness and latitude was not significant (Pearson's $r=0.235, P=0.36$ ).

tiple regression model with PCA axes explained 54\% of the variance in the total observed species richness, whereas the model with eight predictors explained only $19 \%$ of the variance. However, the principal components regression approach is limited by the biological interpretation of the principal components (Graham, 2003). Species richness associated with each dependent variable was significantly correlated with different sets of axes (Table 4), but the relationship between species richness and each environmental variable in the axis was not clearly resolved.

Generally, altitude is higher in the northern and eastern parts of South Korea due to long mountain chains (Mts Taeback), suggesting that the topography varies more in height in eastern and northern quadrates than in western and southern regions (Fig. 1). This topographic gradient was well represented on both sides of the axis in the relationship between species richness and axis 1 (Figs 5, 6). In addition the quadratic increase in species richness along the axis suggests that the predictors of axis 1 contributed equally to the distribution of geometrid moths across the country.

For explaining the pattern of species diversity Rosenzweig (1995) suggests that topographic variation is closely related to habitat diversity. Hawkins \& Porter (2003) showed that topographic variability is not always correlated with habitat heterogeneity or plant diversity (e.g. Kerr et al., 2001; Rahbek \& Graves, 2001). Tews et al. (2004) examined the relationship between habitat heterogeneity and animal species diversity and found a high variability in the relationship, depending on animal group, at different spatial scales. We found that maximum altitude in terms of topographic variability was the best predictor for both observed and estimated species richness of geometrid moths. This was closely related to both latitude (axis 1) and longitude (axis 2), and these predictors combined provided a good indicator of the explanation of the species richness of geometrid moths in South Korea (Table 4).

The effect of environmental factors on the species richness of arthropods is recorded in many studies. Turner et al. (1987) suggest that indicators of energy, such as sunshine and temperature, are the best predictors of the species richness of British butterflies and moths. Similarly, Kerr et al. (1998) suggest that potential evapotranspiration (PET), an energy-related variable, is the best predictor for North American butterflies and forest moths. Kivinen et al. (2006) suggest that species richness of insects such as bees, butterflies and macromoths, is positively correlated with temperature. Baselga (2008) records that the north-to-south gradient of temperature is the main factor affecting species richness of Cerambycid beetles in Europe. Hawkins et al. (2003) indicate that the combined effect of energy and water is critical in the geographic distribution of invertebrates.

Geometrid moths are often physiologically well adapted to cooler conditions (Brehm et al., 2003). The ability to fly at low ambient temperatures is advantageous in severe conditions such as in winter or at high altitudes. In addition, the reduction in predation pressure at high altitudes (Brehm et al., 2003) may result in increased survival. These factors may allow geometrid moths to colonize habitats that are unsuitable for most other insects (Brehm et al., 2003). Brehm et al. (2003) showed that the richness of Ennominae and Larentiinae is either steady or increases with altitude (between 1040 and $2677 \mathrm{~m}$ ) in the Andes. The Larentiine moths show a high species richness in high montane areas (McQuillan, 1986; Holloway, 1987; Brehm et al., 2003). In the present study we found that temperature played an important role in the distribution of geometrid moths in South Korea. Low temperature (axis 1) was the significant predictor of the observed spe-

TABLE 4. Model summary of backward stepwise regression analysis for geometrid moths in 17 quadrates in South Korea against four principal component axes. Each axis variable refers to Table 3. All dependent variables were log-transformed before analyses. Palearctic and Oriental elements were number of species depending on their distributional range. Estimated species richness was not shown since it did not have a statistically significant axis.

\begin{tabular}{lcccccc}
\hline \multirow{2}{*}{ Dependents } & \multirow{2}{*}{$\mathrm{R}_{\text {adj }}{ }^{2}$} & ANOVA & \multicolumn{3}{c}{ Independent variables (b) } \\
\cline { 5 - 7 } & & $F$-ratio & Axis 1 & Axis 2 & Axis 3 & Axis 4 \\
\hline Observed species richness & 0.54 & $7.27^{* *}$ & $0.384^{*}$ & $0.534^{*}$ & & $-0.440^{*}$ \\
Palearctic elements & 0.56 & $7.68^{* *}$ & $0.426^{*}$ & $0.538^{*}$ & & $-0.411^{*}$ \\
Oriental elements & 0.55 & $7.41^{* *}$ & & $0.510^{*}$ & $0.388^{*}$ & $-0.470^{*}$ \\
\hline
\end{tabular}

* $P<0.05, * * P<0.005$. 
cies richness of geometrid moths in South Korea, whereas high temperature (axis 3) was one of the main predictors of the Oriental components of the fauna (Table 4).

Factors influencing the abundance and species richness of geometrid moths are similar regardless of geographic location or time of year. Intachat et al. (2001) show that the abundance of geometrid moths in tropical rain forests is closely related to plant and weather variables. Choi (2008) suggests that abundance of geometrid moths in the southern part of South Korea is related to mean monthly temperature and rainfall. In the present study, the observed species richness of geometrid species in South Korea was significantly related to rainfall (Table 4): species richness increased with rainfall. This finding is consistent with the combined effect of energy and water in warmer climates (Hawkins et al., 2003).

The evolutionary and ecological interactions among moths, butterflies and plants have led to a great diversity of species in both insect groups (Powell et al., 1998), and this may be reflected in the patterns of geometrid moth diversity (e.g. Intachat et al., 2001). We found that vegetation and plant species richness was one of the driving factors of geometrid moth diversity in South Korea (Tables 2, 4). Novotný et al. (2006) suggest that the latitudinal gradient in species diversity of herbivorous insects is closely related to plant diversity; plant diversity drives herbivore insect diversity, especially in the tropics. Beck et al. (2006) also note that vegetation is important for explaining the distribution of sphingid moths on Malesian islands. However, the effect of plant species richness and vegetation on the geometrids of South Korea was relatively weak compared with that of habitat diversity (Table 4). Hawkins \& Porter (2003) suggest that both plants and butterflies in California are affected by similar environmental factors, but plants do not directly affect butterfly diversity. Butterfly species are strongly affected by temperature-related climatic factors (Hawkins et al., 2003; Luoto et al., 2006). This might suggest that both climatic and biotic factors contribute to species diversity in both temperate and tropical areas, but their contribution to the diversity pattern is different depending on whether a region is temperate or tropical.

Among the predictors of the distribution of geometrid moths in South Korea, latitude was found to be one of predictors (axes 1 and 3, Table 3). The decreasing richness with increasing latitude is a well-known global phenomenon and well studied in terms of geometric and climatic predictors (Colwell \& Lees, 2000; Hawkins et al., 2003, 2007). Meanwhile, the pattern of increasing richness with increasing latitude at the regional level represents the "peninsular effect" phenomenon (Simpson, 1964). In the present study, the estimated species richness increased with latitude (Fig. 5), which could account for the peninsular effect on the geometrid moths in South Korea. The peninsular effect is reported for various groups of animals (birds, reptiles, butterflies, sphingid moths) and plants on different peninsulas, such as Baja California, Maine, Florida, Iberia, northern Thailand and Australia (Wiggins, 1999; Beck et al., 2007; Tubelis et al., 2007). On the Korean peninsula, butterflies (Choi, 2004) exhibit a similar peninsular effect to geometrid moths.

Different ecological and evolutionary models are used to explain the peninsular effect: immigration and extinction dynamics, environmental factors (e.g. habitat diversity, climate, topography and floral diversity) and historical factors (e.g. palaeogeography) (Wiggins, 1999; Tubelis et al., 2007). Throughout the present study, both decreasing species richness from the bases to the ends of peninsulas and spatial autocorrelation of moths were attributable to immigration-extinction dynamics (MacArthur \& Wilson, 1967). Nevertheless, it could be concluded that the geographic distribution of geometrid moths in South Korea resulted from the combined effect of spatial (latitude, longitude, maximum altitude) and environmental (temperature, rainfall, plants) factors.

ACKNOWLEDGEMENTS. We thank J.-S. An, M. Park (MNU) for compiling data and drawing the map, and J.C. Miller (Oregon State University), two anonymous referees and M. Konvička (editor) for commenting on the manuscript. This study was supported by the Korea Research Foundation funded by the Korean Government (MOEHRD) (KRF grant no. 2007C00590).

\section{REFERENCES}

Axmacher J.C., Holtmann G., Scheuermann L., Brehm G., Müller-Hohenstein K. \& Fiedler K. 2004: Diversity of geometrid moths (Lepidoptera: Geometridae) along an Afrotropical elevational rainforest transect. Divers. Distrib. 10: 293-302.

Baselga A. 2008: Determinants of species richness, endemism and turnover in European longhorn beetles. Ecography 31: 263-271.

Beck J., Schulze C.H., Linsenmair K.E. \& Fiedler K. 2002: From forest to farmland: diversity and community structure of geometrid moths along two habitat gradients on Borneo. $J$. Trop. Ecol. 17: 33-51.

Beck J., Kitching I.J. \& Linsenmair K.E. 2006: Determinants of regional species richness: an empirical analysis of the number of hawkmoth species (Lepidoptera: Sphingidae) on the Malesian archipelago. J. Biogeogr. 33: 694-706.

Beck J., Kitching I.J. \& Hazaire J. 2007: The latitudinal distribution of sphingid species richness in continental Southeast Asia: What causes the biodiversity "Hot spot" in northern Thailand? Raffles Bull. Zool. 55: 179-185.

BReHM G. \& FiedLeR K. 2003: Faunal composition of geometrid moths changes with altitude in an Andean montane rainforest. Ecography 26: 456-466.

Brehm G., Süssenbach D. \& Fiedler K. 2003: Unique elevational diversity patterns of geometrid moths in an Andean montane rainforest. Ecography 26: 456-466.

Chо S.-W. 2004: Trends in butterfly species richness in response to the peninsular effect in South Korea. J. Biogeogr. 31: $587-592$.

CHOI S.-W. 2006: Patterns of species description and species richness of Geometrid moths (Lepidoptera: Geometridae) on the Korean peninsula. Zool. Sci. 23: 155-160.

CHOI S.-W. 2008: Effects of weather factors on the abundance and diversity of moths in a temperate deciduous mixed forest of Korea. Zool. Sci. 25: 53-58.

Colwell R.K. 2006: EstimateS: Statistical Estimation of Species Richness and Shared Species from Samples. Version 8.0. 
User's Guide and application published at: http://purl.oclc. org/estimates.

Colwell R.K. \& Coddington J.A. 1994: Estimating terrestrial biodiversity through extrapolation. Phil. Trans. R. Soc. Lond. (Biol. Sci.) 345: 101-118.

Colwell R.K. \& Lees D.C. 2000: The mid-domain effect: geometric constraints on the geography of species richness. Trends Ecol. Evol. 15: 70-76.

Dennis R.L.H., Sparks T.H. \& Hardy P.B. 1999: Bias in butterfly distribution maps: the effect of sampling effort. $J$. Insect Conserv. 3: 33-42.

FIELD A. 2000: Discovering Statistics Using SPSS for Windows. SAGE Publications, London, $496 \mathrm{pp}$.

Graham M.H. 2003: Confronting multicollinearity in ecological multiple regression. Ecology 84: 2809-2815.

Hawkins B.A. \& Porter E.E. 2003: Does herbivore diversity depend on plant diversity? The case of California Butterflies. Am. Nat. 161: 40-49.

Hawkins B.A., Field R., Cornell H.V., Currie D.J., Guégan J-F., Kaufmann D.M., Kerr J.T., Mittelbach G.G., OberdorfF T., O'Brien E.M., Porter E.E. \& Turner J.R.G. 2003: Energy, water, and broad-scale geographic patterns of species richness. Ecology 84: 3105-3117.

Hawkins B.A., Albuquerque F.S., Araújo M.B., Beck J., Bin L.M., Cabrero-Sañudo F.J., Castro-Parga I., Diniz-Felho J.A.F., Ferrer-Castán D., Field R., Gómez J.F., Hortal H., Kerr J.T., Kitching I., LeÓn-Cortés J.L., Lobo J.M., Montoya D., Moreno J.C., Olalla-Tárraga M.Á., Pausas J.G., Qian H., Pahbeck C., Rodriquez M.Á., Sander N.J. \& WilLIAMS P. 2007: A global evaluation of metabolic theory as an explanation for terrestrial species richness gradients. Ecology 88: $1877-1888$.

Holloway J.D. 1987: Macrolepidoptera diversity in the IndoAustralian tropics: Geographic, biotopic and taxonomic variations. Biol. J. Linn. Soc. 30: 325-341.

Hortal J., Garcia-Pereira P. \& García-Barros E. 2004: Butterfly species richness in mainland Portugal: predictive models of geographic distribution patterns. Ecography 27: $68-82$.

Intachat J., Holloway J.D. \& Staines H. 2001: Effects of weather and phenology on the abundance and diversity of geometrid moths in a natural Malaysian tropical rain forest. $J$. Trop. Ecol. 17: 411-429.

Kerr J.T., Vincent R. \& CurRie D.J. 1998: Lepidopteran richness patterns in North America. Ecoscience 5: 448-453.

Kerr J.T., Southwood R.E. \& Cihlar J. 2001: Remotely sensed habitat diversity predicts butterfly species richness and community similarity in Canada. Proc. Nat. Acad. Sci. USA 98: 11365-11370.

Kivinen S., Luoto M., Kuussaari M. \& Helenius J. 2006: Multiscale richness of boreal agricultural landscapes: effects of climate, biotope, soil and geographical location. J. Biogeogr. 33: $862-875$.

Legendre P. \& Legendre L. 1998: Numerical Ecology. 2nd ed. Elsevier, Amsterdam, $853 \mathrm{pp}$

Lobo J.M., CAstro I. \& Moreno J.C. 2001: Spatial and environmental determinants of vascular plant species richness distri- bution in the Iberian Peninsula and Balearic Islands. Biol. J. Linn. Soc. 73: 233-253.

Luoto M., Heikkinen R.K., Pöyry J. \& SaArinen K. 2006: Determinants of the biogeographical distribution of butterflies in boreal regions. J. Biogeogr. 33: 1764-1778.

MacArthur R.H. \& WiLson E.O. 1967: The Theory of Island Biogeography. Princeton Univ. Press, Princeton, 203 pp.

MaC NAlly R. 2000: Regression and model-building in conservation biology, biogeography and ecology: the distinction between - and reconciliation of - "predictive" and explanatory models. Biodivers. Conserv. 9: 655-671.

McCune B. \& MefFord M.J. 2006: PC-ORD. Multivariate Analysis of Ecological Data. Version 5.12. MjM Software, Gleneden Beach, Oregon.

McQuillan P.B. 1986: Trans-Tasman relationships in the highland moth (Lepidoptera) fauna. In Barlow B.A. (ed.): Flora and Fauna of Alpine Australasia Ages and Origins. CSIRO, Canberra, pp. 265-276.

Novotný V., Drozd P., Miller S.E., Kulfan M., Janda M., BAsSet Y. \& Weilbblen G.D. 2006: Why are there so many species of herbivorous insects in tropical rainforests? Science 313: $1115-1118$.

Powell J.A., Mitter C. \& Farrell B. 1998: Evolution of larval food preferences in Lepidoptera. In Kristensen N.P. (ed.): Lepidoptera, Moths and butterflies. Vol. 1. Evolution, Systematics and Biogeography. Handbook of Zoology. Vol. IV. Arthropoda: Insecta. Walter de Gruyter, Berlin, pp. 403-422.

RahbeK C. \& Graves G.R. 2001: Multiscale assessment of patterns of avian species richness. Proc. Nat. Acad. Sci. USA 98: 4534-4539.

Rosenzweig M.L. 1995: Species Diversity in Space and Time. Cambridge University Press, Cambridge, $436 \mathrm{pp}$.

Scoble M.J. 1999: Geometrid Moths of the World: A Catalogue (Lepidoptera: Geometridae), Vols 1 and 2. Apollo Books, Stenstrup, $116 \mathrm{pp}$.

SHIN Y.-H. 1996: Synonymic List and Distribution of the Geometridae of Korea (Lepidoptera). Center for Insect Systematics, Chuncheon, $153 \mathrm{pp}$.

Shin J.-H. 2002: Ecosystem geography of Korea. In Lee D. (ed.): Ecology of Korea. Bumwoo Publishing, Seoul, pp. $19-46$.

Simpson G.G. 1964: Species densities of North American recent mammals. Syst. Zool. 13: 57-73.

SPSS INC. 2005: SPSS for Windows 12.0. SPSS Inc., Chicago.

Tews J., Brose U., Grimm V., Tielbörger K., Wichmann M.C., Schwager M. \& Jeltsch F. 2004: Animal species diversity driven by habitat heterogeneity/diversity: the importance of keystone structures. J. Biogeogr. 31: 79-92.

Tubelis D.P., Lindenmayer D.B. \& Cowling A. 2007: The peninsular effect on bird species in native eucalypt forests in a wood production landscape in Australia. J. Zool. 271: 11-18.

Turner J.R.G., Gatehouse C.M. \& Corey C.A. 1987: Does solar energy control organic diversity? Butterflies, moths and the British climate. Oikos 48: 195-205.

WIGGINS D.A. 1999: The peninsular effect on species diversity: a reassessment of the avifauna of Baja California. Ecography 22: $542-547$.

Received May 26, 2008; revised and accepted September 24, 2008 